\title{
Relationship between social mentality and urban social adaptation of new citizens in the process of China's urbanization
}

\author{
Xiao-bing Xie ${ }^{1}$, Xiao-fu Pan ${ }^{1,2, *}$, Kai Du ${ }^{1}$ \\ ${ }^{1}$ School of Culture \& Social Development Studies, Southwest University, Chongqing, China \\ ${ }^{2}$ Research Center of Psychology and Social Development, Southwest University, Chongqing, China
}

Email address:

smilepxf@126.com (Xiao-fu Pan), xiabing0729@qq.com (Xiao-bing Xie), dukai0929@126.com (Kai Du)

To cite this article:

Xiao-bing Xie, Xiao-fu Pan, Kai Du. Relationship between Social Mentality and Urban Social Adaptation of New Citizens in the Process of China's Urbanization. American Journal of Applied Psychology. Vol. 3, No. 4, 2014, pp. 92-98. doi: 10.11648/j.ajap.20140304.12

\begin{abstract}
This study explored the relationship between social mentality and urban social adaptation of new citizens in China's urbanization process. 580 new citizens have been tested in the study. The results are as follows: Firstly, new citizens have the high sense of trust in the government, social problems and social stress, while they have the low sense of social fair; new citizens' urban social adaptation conditions are a little worse, especially for the adaptation of job and values about life. Secondly, new citizen who has a higher levels of education, longer citizen's experience and better economic conditions, will have a better social adaptability. Thirdly, social mentality is significant predictive variable of urban social adaptation. Specifically, sense of life satisfaction, sense of social fair and trust in the government are significant and positive predictor of new citizens' urban social adaptation, and sense of social stress and social problems are significantly negative effect of prediction on new citizens' urban social adaptation.
\end{abstract}

Keywords: Urbanization, New Citizens, Social Mentality, Urban Social Adaptation

\section{Introduction}

Since the reform and opening up, along with the accelerated process of industrialization, China's urbanization has experienced a fast development epoch. In 1978-2013, the urban resident population from 170 million to 730 million, the urbanization rate increased from $17.9 \%$ to $53.7 \%$, an average increase of $1.02 \%$; number of cities from 193 to 658, the number of towns from 2173 to 20113. This extensive urbanization has spawned a large number of new citizens. Only in Chongqing city, from 2010 to 2020, it is predicted that 10 million farmers would migrate to cities, transfer their registered permanent residences and then become new citizens.

For new citizens who moved from their rural hometown to the cities, the urbanization is not only means a transformation of geographically, but also means a totally transfer and change from ideological concepts to behaviors, mental consciousness to the systems in which they live. It is a complex and profound process of social adaptation. So, in China's urbanization process, what is the situation of new citizens' urban social adaptation? How is their social mentality? Whether the social mentality influences their urban social adaption or not? This study aims to explore the relationship between social mentality and social adaptation of new citizens in China's urbanization process.

\section{Literature Review}

Social adaptation is constantly a hot issue, and many researchers who live in the domestic and foreign pay close attention to focus on it, especially in the period when human's living space and social environment are transferring and changing, such as immigrants and new citizens in urbanization. In previous studies, researchers mainly focused on the definition of social adaptation. There were many different definitions. For example, Leland (1973) and Cone (1987) suggested that social adaptation was the reply of social culture, values and lifestyles in the interaction between individual and social environment[1]. Arthur Reber (1985) suggested that social adaptation referred to the change of society or cultural trends [2]. Zhu 
Zhixian (1989) argued that social adaptation refers to "individuals accept the existing social life style, ethics and code of conduct process [3]. Lukas (2005) thought that social adaptation was an interactive process between social environment and individuals or groups, in this process, participants' needs were harmonious with their wills [4]. Chen Jianwen and Wang Tao (2003) believed that social adaptation was a process aimed to a balance between individual and social environment in the interaction between them [5]. Besides, some psychologists suggested that social adaptation referred to an adaptation of social life environment, which includes making own behavior meet social requirements and trying best to change environment for a better developmental adaptation in order to survive ( $\mathrm{Jia}$ Xiaobo,2001 ) [6]. Xu Hongyu (2009) and some other researchers had preliminarily explored the social adaptation conditions of Chinese veterans from aspects of psychological and external factors [7]. Ye Jihong (2008) had mainly explored urban adaptation of landless peasants from aspects of urban employment, social interaction, social psychology and identities. These researchers suggested that the nature of landless peasants' social adaptation was cultural adaptation [8]. Feng Xiaotian (2005) suggested that social adaptation included behavioral adaptation and psychological adaptation [9].

In summary, this study suggests that new citizens' urban social adaptation refers to a new city resident have an understanding of life and economic environment, interpersonal communication and cultural concepts, individual subjective world and the social environment in the interaction process, and they take proactive change according to the changes in the environment. New Citizens' social adaptation include: in the process of adapt to the social environment, individual can use the existing environmental conditions, constantly change life, behavior and way of thinking to excavate the potential of their own, enhance the value of self. On the contrary, maybe the individual will not strive to make progress in the process, which results in the stagnation, because of the individual contenting with mediocrity and being live conditions.(Chen Jianwen \&Wang Tao , 2004) [10]. Engel (1977) pointed out that the social adaptation is an important standard of mental health [11], which is the result of criminal conducting due to social maladjustment. Bartol (2005) believed that early social maladjustment individuals prone to mental health problems, are more likely to produce adverse effects on the behavior of others and the social problems and criminal behavior [12]. Therefore, promotion of new citizens to better adapt to the urban environment, to better integrate into the city, more healthy development, but an important topic of social transformation in Chinese society, for building a harmonious society, maintaining social stability is very urgent and important.

Whether in the human history since birth or in the life of people, the social mentality plays an irreplaceable role and this role is growing more and more, therefore, it arouses people's great concern. Social mentality is a universal social psychological feelings and reactions that is taken placed by interaction between individuals or social groups and the social reality in a certain historical period (Yifu Wang \& Xiaofu Pan, 2013) [13]. It has an intermediary filter function, bidirectional effect and self regulation efficiency based on a perspective of the historical values and social epistemology. As we all known, a good attitude helps the formation of new social and moral value system, to create a good social climate, and promote the orderly development of the market economy. Negative social mentality may make a crisis of faith increased, increasing social instability and hamper the social progress (Cheng Jiaming, 2009) [14].

As for new citizens, with the changing of living environment, behavior and lifestyle, "survival in cities" means "adaptation" in fact. Studies have shown that new citizens' social adaptation is affected by various factors, such as urban-rural dual system, self-identity urban population differences and cultural conflict existing in cities and country and social support (Li Liwen \&Yu chong, 2006) [15]. In their city adaptation process, the sense of relative deprivation, the sense of social differences and the sense of social distance of new citizens lead to an influence on new citizens' social mentality. At the same time, the social mentality is a direct reflection of social existence and it will act on social existence more directly. Changes in social mentality may occur during the social adaptation process. Tang Liping (2005) studied on the marginalized selfrecognition of inter-provincial migrants, and pointed out that the social mentality has influence on the adaptation of new culture and social life [16]. Liu Zhen \& Lei Hong (1999) pointed out in their study on social mentality of the Three Gorges Migrants in social adaptation process that when the Three Gorges Migrants got socialized and achieved social adaptation, their own subjective initiative played a vital part in this process. Meanwhile, social mentality was a concentrated expression for their subjective initiative and a basis of their socialized behaviors to get adapted to new environment [17]. But what is the relationship between new citizens' social mentality and social adaptation during Chinese urbanization? Currently, there is lack of supports from empirical evidence.

Therefore, this study is attempting to explore the relationship between new citizens' social mentality and urban social adaptation, so that to provide a theoretical foundation for promoting social stability and constructing a harmonious society.

\section{Methods}

\subsection{Participants}

603 participants were chosen by stratified-random sampling method from 72 communities of 25 different districts in Chongqing Municipality. The 580 valid copies got recovered from 603 questionnaires with returns-ratio $96.1 \%$. The basic status of participants are shown in Table 1 . 


\subsection{Measures}

\subsubsection{The New Citizen Urban Social Adaptation Scale}

All participants were measured using the new citizen urban social adaptation scale (Kai Du \& Xiaofu Pan, 2014), which includes five dimensions: work adaptation, environment adaptation, interpersonal adaptation, values for adaptation and psychological adaptation [18]. Reliability analysis shows the Cronbach's $\alpha$ of the whole scale is 0.908 , and the Cronbach's $\alpha$ of each subscale is above 0.70 . Meanwhile, validity analysis indicates the scale has a high validity. The scale includes 43 items, and each item of scale was used a 5 point Likert scale $(1=$ strongly disagree, $5=$ strongly agree). The higher score, the higher adaptation to urban society.

\subsubsection{The Chinese Social Mentality Scale}

All participants also were measured using the Chinese Social Mentality Scale (Yifu Wang \& Xiaofu Pan, 2013) [19], which includes 60 items. And the scale has six dimensions: sense of life satisfaction, sense of social stress, sense of trust in the government, sense of social fair, sense of social safety, sense of social problem. The each item of scale was used a 5 point Likert scale. Results show that the questionnaire has good reliability and validity.

\subsection{Procedure}

According to three levels of the community (large, medium and small), 603 participants (male $\mathrm{N}=319$, female $\mathrm{N}=261$ ) were chosen by stratified-random sampling method from 72 communities of 25 different districts in Chongqing. And With uniform instruction, highly trained staff ask participants to answer the anonymous questionnaire. The 580 valid copies were token back from 603 questionnaires with returns-ratio $96.1 \%$. Then all data would be analyzed using statistical software SPSS20.0 for Windows.

\section{Results}

\subsection{The Descriptive Analysis of All Variables}

Having done the descriptive statistical analysis of new citizens' demographic variables and other related variables as well as social mentality and social adaptation, the results are shown in Table 1.

It is shown in Table 1 that scores obtained by new citizens for social adaptation are low in general (scoring above 3 can be defined as adapted), indicating that new citizens don not get healthily adapted to urban society. Meanwhile, scores are below average on five factors of social adaptation, especially on factors of work adaptation and value for adaptation (scoring below 2 can be defined as maladapted), which shows there are more severe maladaptation problems in new citizens' life on above respects. As for social mentality, new citizens are about average with a higher sore in the sense of social problems and the sense of trust in government but a lower score in the sense of social fair, and scoring of the sense of life satisfaction and the sense of social safety being in the medium level. The data of Table1 reveals new citizens can experience many social problems in their life, such as social wealth gap, housing, employment, pension, problems of medical treatment and health insurance and so on, contributing to their high sense of social stress and a low sense of social fair, but they with a higher trust in government to whom new citizens hold a supportive attitude.

Table 1. descriptive results $(N=580)$

\begin{tabular}{|c|c|c|}
\hline & Mean (\%) & SD \\
\hline \multicolumn{3}{|l|}{ Age (in years) } \\
\hline$\leqslant 35$ & 43.6 & \\
\hline $35 \sim 55$ & 52.4 & \\
\hline$\geqslant 55$ & 4.00 & \\
\hline \multicolumn{3}{|l|}{ Gender (\%) } \\
\hline Male & 55.0 & \\
\hline Female & 45.0 & \\
\hline \multicolumn{3}{|l|}{ Marital status (\%) } \\
\hline Married & 79.1 & \\
\hline Unmarried & 16.6 & \\
\hline Divorced & 4.30 & \\
\hline \multicolumn{3}{|l|}{ Education (\%) } \\
\hline Junior and High school & 74.0 & \\
\hline Junior college & 13.6 & \\
\hline University and higher & 12. & \\
\hline \multicolumn{3}{|l|}{ Rural/urban residence previously (\%) } \\
\hline Living in rural village & 61.9 & \\
\hline Living in urban community & 38.1 & \\
\hline \multicolumn{3}{|l|}{ Time of living the city (in year,\%) } \\
\hline$\leqslant 3$ & 22.4 & \\
\hline $3 \sim 5$ & 24.7 & \\
\hline $5 \sim 10$ & 29.8 & \\
\hline$\geqslant 10$ & 23.1 & \\
\hline \multicolumn{3}{|c|}{ Time of becoming new civil (in year,\%) } \\
\hline$\leqslant 1$ & 38.3 & \\
\hline $1 \sim 3$ & 32.2 & \\
\hline $3 \sim 5$ & 11.9 & \\
\hline$\geqslant 5$ & 17.6 & \\
\hline \multicolumn{3}{|l|}{ Status of economic (\%) } \\
\hline Poor & 12.8 & \\
\hline Medium & 74.4 & \\
\hline Rich & 14.8 & \\
\hline Social adaptation & 2.86 & 0.46 \\
\hline Environmental adaptation & 2.62 & 0.72 \\
\hline Values for adaption & 3.00 & 0.77 \\
\hline Interpersonal adaptation & 2.84 & 0.63 \\
\hline Work adaptation & 3.06 & 0.64 \\
\hline Mental adaptation & 2.80 & 0.61 \\
\hline Social mentality & 3.20 & 0.40 \\
\hline Sense of life satisfaction & 3.14 & 0.67 \\
\hline Sense of social stress & 3.27 & 0.65 \\
\hline Sense of trust in the government & 3.48 & 0.75 \\
\hline Sense of social fair & 2.71 & 0.92 \\
\hline Sense of social safety & 3.03 & 0.69 \\
\hline Sense of social problem & 3.59 & 0.69 \\
\hline
\end{tabular}

\subsection{Correlation Analysis of New Citizens' Urban Social Adaption and Social Mentality}

Shown in Table 2 are the results of correlation matrix analysis from new citizens' social adaptation, social mentality and demographic variables. 
Table 2. Correlation analysis of new citizens'social adaption and social mentality $(n=580)$

\begin{tabular}{|c|c|c|c|c|c|c|c|c|c|c|c|c|c|c|c|c|c|c|c|}
\hline & 1 & 2 & 3 & 4 & 5 & 6 & 7 & 8 & 9 & 10 & 11 & 12 & 13 & 14 & 15 & 16 & 17 & 18 & 1 \\
\hline 1.Age & 1 & & & & & & & & & & & & & & & & & & \\
\hline 2.Marital & $\begin{array}{l}-.14^{*} \\
*\end{array}$ & 1 & & & & & & & & & & & & & & & & & \\
\hline $\begin{array}{l}\text { 3.Educati } \\
\text { on }\end{array}$ & $\begin{array}{l}-.39^{*} \\
*\end{array}$ & $\begin{array}{l}.18^{*} \\
*\end{array}$ & 1 & & & & & & & & & & & & & & & & \\
\hline 4.RURP & .06 & .04 & $\begin{array}{l}.12 * \\
*\end{array}$ & 1 & & & & & & & & & & & & & & & \\
\hline 5.TBNC & -.04 & $\begin{array}{l}.14^{*} \\
*\end{array}$ & $\begin{array}{l}.18^{*} \\
*\end{array}$ & -.01 & 1 & & & & & & & & & & & & & & \\
\hline 6. SE & -.04 & -.01 & .07 & $\begin{array}{l}.13^{*} \\
*\end{array}$ & .01 & 1 & & & & & & & & & & & & & \\
\hline 7.EA & -.05 & -.03 & -.04 & .04 & .01 & -.07 & 1 & & & & & & & & & & & & \\
\hline 8.IA & .04 & -.07 & $-.10^{*}$ & $\begin{array}{l}-.13^{*} \\
*\end{array}$ & $\begin{array}{l}.12^{*} \\
*\end{array}$ & $\begin{array}{l}-.25^{*} \\
*\end{array}$ & $\begin{array}{l}.53^{*} \\
*\end{array}$ & 1 & & & & & & & & & & & \\
\hline 9.IPA & .04 & -.08 & $-.09^{*}$ & $-.09^{*}$ & .06 & $\begin{array}{l}-.18 * \\
*\end{array}$ & .02 & $\begin{array}{l}.15^{*} \\
*\end{array}$ & 1 & & & & & & & & & & \\
\hline 10.WA & -.01 & .01 & $-.10^{*}$ & $\begin{array}{l}-.11^{*} \\
*\end{array}$ & $.09 *$ & $\begin{array}{l}-.25^{*} \\
*\end{array}$ & $\begin{array}{l}.58^{*} \\
*\end{array}$ & $\begin{array}{l}.60^{*} \\
*\end{array}$ & $.09^{*}$ & 1 & & & & & & & & & \\
\hline 11.MA & .05 & -.04 & $-.10^{*}$ & $\begin{array}{l}-.11 * \\
*\end{array}$ & .03 & $\begin{array}{l}-.25^{*} \\
*\end{array}$ & $\begin{array}{l}.27^{*} \\
*\end{array}$ & $\begin{array}{l}.25^{*} \\
*\end{array}$ & $\begin{array}{l}.40^{*} \\
*\end{array}$ & $\begin{array}{l}.33^{*} \\
*\end{array}$ & 1 & & & & & & & & \\
\hline 12.SLS & .06 & -.01 & $.08 *$ & .04 & -.02 & $\begin{array}{l}.18^{*} \\
*\end{array}$ & $\begin{array}{l}-.28^{*} \\
*\end{array}$ & $\begin{array}{l}-.23 * \\
*\end{array}$ & $\begin{array}{l}-.22^{*} \\
*\end{array}$ & $\begin{array}{l}-.36^{*} \\
*\end{array}$ & $\begin{array}{l}-.56^{*} \\
*\end{array}$ & 1 & & & & & & & \\
\hline 13.SSS & -.05 & -.01 & .01 & .01 & -.05 & $-.10^{*}$ & $\begin{array}{l}.38^{*} \\
*\end{array}$ & $\begin{array}{l}.35^{*} \\
*\end{array}$ & .07 & $\begin{array}{l}.41^{*} \\
*\end{array}$ & $\begin{array}{l}.20^{*} \\
*\end{array}$ & $\begin{array}{l}-.34 * \\
*\end{array}$ & 1 & & & & & & \\
\hline 14.STG & $.10^{*}$ & $-.10^{*}$ & -.04 & $\begin{array}{l}.13^{*} \\
*\end{array}$ & $\begin{array}{l}-.11 * \\
*\end{array}$ & $\begin{array}{l}.13^{*} \\
*\end{array}$ & $\begin{array}{l}-.25^{*} \\
*\end{array}$ & $\begin{array}{l}-.15^{*} \\
*\end{array}$ & $\begin{array}{l}-.14 * \\
*\end{array}$ & $\begin{array}{l}-.25 * \\
*\end{array}$ & $\begin{array}{l}-.35^{*} \\
*\end{array}$ & $\begin{array}{l}.48^{*} \\
*\end{array}$ & $\begin{array}{l}-.14^{*} \\
*\end{array}$ & 1 & & & & & \\
\hline 15.SSF & $.09 *$ & -.06 & -.05 & .05 & -.07 & .06 & .04 & .03 & $\begin{array}{l}-.11 * \\
*\end{array}$ & -.06 & $\begin{array}{l}-.28 * \\
*\end{array}$ & $\begin{array}{l}.51^{*} \\
*\end{array}$ & $\begin{array}{l}-.13^{*} \\
*\end{array}$ & $\begin{array}{l}.46^{*} \\
*\end{array}$ & 1 & & & & \\
\hline 16.SOSS & $.12 * *$ & $\begin{array}{l}-.14^{*} \\
*\end{array}$ & $-.10^{*}$ & .01 & $-.09 *$ & -.03 & $-.10^{*}$ & .01 & $\begin{array}{l}-.11^{*} \\
*\end{array}$ & $-.09 *$ & $\begin{array}{l}-.33^{*} \\
*\end{array}$ & $\begin{array}{l}.46^{*} \\
*\end{array}$ & $\begin{array}{l}-.16^{*} \\
*\end{array}$ & $\begin{array}{l}.54 * \\
*\end{array}$ & $\begin{array}{l}.66^{*} \\
*\end{array}$ & 1 & & & \\
\hline 17.SSP & -.07 & .07 & $\begin{array}{l}.12^{*} \\
*\end{array}$ & -.01 & -.02 & .06 & -.01 & .06 & -.03 & .02 & .05 & $\begin{array}{l}-.16^{*} \\
*\end{array}$ & $\begin{array}{l}.41^{*} \\
*\end{array}$ & -.02 & $\begin{array}{l}-.17^{*} \\
*\end{array}$ & $\begin{array}{l}-.17^{*} \\
*\end{array}$ & 1 & & \\
\hline 18.SPS & $.08^{*}$ & -.08 & -.01 & .08 & $\begin{array}{l}-.11 * \\
* \\
*\end{array}$ & $.09^{*}$ & -.07 & .02 & $\begin{array}{l}-.17^{*} \\
*\end{array}$ & $\begin{array}{l}-.11 * \\
* \\
*\end{array}$ & $\begin{array}{l}-.39 * \\
*\end{array}$ & $\begin{array}{l}.61^{*} \\
*\end{array}$ & $\begin{array}{l}.15^{*} \\
*\end{array}$ & $\begin{array}{l}.73^{*} \\
*\end{array}$ & $\begin{array}{l}.77^{*} \\
*\end{array}$ & $\begin{array}{l}.74 * \\
*\end{array}$ & $\begin{array}{l}.23 * \\
*\end{array}$ & 1 & \\
\hline 19.SA & .02 & -.06 & $\begin{array}{l}-.12^{*} \\
*\end{array}$ & $\begin{array}{l}-.12^{*} \\
*\end{array}$ & $.09^{*}$ & $\begin{array}{l}-.29 * \\
*\end{array}$ & $\begin{array}{l}.73^{*} \\
*\end{array}$ & $\begin{array}{l}.78^{*} \\
*\end{array}$ & $\begin{array}{l}.46^{*} \\
*\end{array}$ & $\begin{array}{l}.78^{*} \\
*\end{array}$ & $\begin{array}{l}.64 * \\
*\end{array}$ & $\begin{array}{l}-.47^{*} \\
*\end{array}$ & $\begin{array}{l}.42^{*} \\
*\end{array}$ & $\begin{array}{l}-.33^{*} \\
*\end{array}$ & $-.10^{*}$ & $\begin{array}{l}-.17^{*} \\
*\end{array}$ & .03 & $\begin{array}{l}-.20^{*} \\
*\end{array}$ & 1 \\
\hline
\end{tabular}

Notes: $* \mathrm{P}<0.01,{ }^{*} \mathrm{P}<0.001$, two tailed test; Age: $1=$ under the age of $35,2=$ age $35 \sim 55,3=$ above $55 ; \quad$ Level of Education: $1=$ under junior high school, 2= senior high school / technical secondary school, 3= above college; RURP: Rural/urban residence previously, $1=$ rural,2=urban; TBNC: Time of becoming new civil, $1=$ under 1 year, $2=1 \sim 3$ years,3=3 5years,4=above 5years; SE: Status of economic,1=poor,2=medium,3=rich; EA: Environmental adaptation ;IA: Ideal adaption; IPA: Interpersonal adaptation; WA: Work adaptation; MA: Mental adaptation; SLS: Sense of life satisfaction; SSS: Sense of social stress; STG: Sense of trust in the government; SSF: Sense of social fair; SOSS: Sense of social safety; SSP: Sense of social problem; SPS: Social psychological status; SA: social adaption

It is can be seen from Table 2 that there is significant correlation between new citizens' age and their sense of trust in government, social fair and social safety, but no significant correlation between their age and social adaptation; new citizens' marital status is only significantly correlated with their sense of social fair and sense of trust in government; and their level education is significantly correlated with their sense of life satisfaction, social safety and social problems, also has significant correlation with values for adaptation, interpersonal adaptation, work adaptation and mental adaptation; meanwhile, there is significant correlation between rural/urban residence previously and sense of trust in government, values for adaptation, interpersonal adaptation, work adaptation and mental adaptation; and time of becoming new citizen is significantly correlated with social mentality, the sense of trust in government and social safety as well as values for adaptation and work adaptation; having significant correlation with their sense of life satisfaction, trust in government and social safety, economic condition is also significantly correlated with values for adaptation, interpersonal adaptation, work adaptation and mental adaptation. Viewed from direction of correlation, factors of the sense of life satisfaction, trust in government, social fair and social safety have significant positive correlation with social adaptation, while the sense of social stress and social problems have significant negative correlation with social adaptation. 


\subsection{Regression Analysis of Social Mentality and Social Adaptation}

The stepwise regression analysis was conducted, using social adaptation as dependent variable and each demographic variable of new citizens and all variables in social mentality as independent variable, and results are presented in Table 3.

It is illustrated in Table 3. Firstly, new citizens can achieve a better social adaptation when they get a higher education level, a longer time for being new citizen and a better economic condition, explaining $11.6 \%$ of variance. Secondly, the higher their life satisfaction is, the better they get adapted to city life; and the greater social stress is, the less they can get social adaptation. Thirdly, the more they sense social fair and trust in government, the better they fit into the society, however, the more they experience social problems, the worse they fit into the society. Fourthly, key factors affecting new citizens' social adaptation are the sense of life satisfaction, the sense of social stress, the sense of social fair and the sense of trust in government, respectively explaining $17.6 \%, 7.7 \%, 3 \%, 1.2 \%$ of the variances and accounting for $29.5 \%$ of variance in total, but the effect of the sense of social safety has no significant.

Table 3. Hierarchical regression analyses of social mentality on social adaption $(n=580)$

\begin{tabular}{|c|c|c|c|c|c|c|c|}
\hline \multirow{2}{*}{ Argument } & \multicolumn{7}{|c|}{ Standard Regression Coefficient } \\
\hline & Step 1 & Step 2 & Step3 & Step4 & Step5 & Step6 & Step7 \\
\hline Age & .037 & -.012 & -.018 & -.022 & -.019 & -.019 & -.021 \\
\hline Marital status & .059 & .065 & .063 & $.071 *$ & $.068 *$ & $.071 *$ & $.066^{*}$ \\
\hline Education & $.127 * *$ & .074 & $.083 *$ & $.090 *$ & $.077 *$ & $.079 *$ & .066 \\
\hline RURP & .061 & .064 & $.072 *$ & .057 & .060 & .061 & $.067 *$ \\
\hline TBNC & $.118 * *$ & $.102 * *$ & $.120 * * *$ & $.110 * * *$ & $.112 * *$ & $.112 * * *$ & $.109 * *$ \\
\hline SE & $.275^{* * *}$ & $.201 * *$ & $.187 * * *$ & $.182 * * *$ & $.173 * * *$ & $.177 * * *$ & $.167 * * *$ \\
\hline SLS & & $.430 * * *$ & $.329 * * *$ & $.268 * * *$ & $.353 * * *$ & $.350 * * *$ & $.351 * * *$ \\
\hline SSS & & & $-.297 * * *$ & $-.301 * * *$ & $-.292 * * *$ & $-.291 * * *$ & $-.335 * * *$ \\
\hline STG & & & & $.129 * *$ & $.185 * * *$ & $.175 * * *$ & $.159 * * *$ \\
\hline SSF & & & & & $.211 * * *$ & $.229 * * *$ & $.217 * * *$ \\
\hline SOSS & & & & & & .038 & .048 \\
\hline SSP & & & & & & & $-.110 * *$ \\
\hline Adjusted $\mathrm{R}^{2}$ & .107 & .284 & .361 & .372 & .401 & .401 & .409 \\
\hline$\Delta \mathrm{R}^{2}$ & .116 & .176 & .077 & .012 & .030 & .001 & .009 \\
\hline$F(6,578)$ & $12.55 * * *$ & $33.71 * * *$ & $41.79 * * *$ & $39.05 * * *$ & $39.73 * * *$ & $36.15 * * *$ & $34.39 * * *$ \\
\hline
\end{tabular}

Notes: $* \mathrm{p}<0.05, * * \mathrm{p}<0.01, * * * \mathrm{p}<0.001$; Age: $1=$ under the age of $35,2=$ age $35 \sim 55,3=$ above 55 ; Level of Education: $1=$ under junior high school, $2=$ senior high school / technical secondary school, 3= above college; RURP: Rural/urban residence previously,1=rural,2=urban; TBNC: Time of becoming new civil,1= under 1year,2=1 3 years,3=3 5years,4=above 5years; SE: Status of economic, $1=$ poor,2=medium,3=rich; SLS: Sense of life satisfaction; SSS: Sense of social stress; STG: Sense of trust in the government; SSF: Sense of social fair; SOSS: Sense of social safety; SSP: Sense of social problem

\section{Discussion}

\subsection{Status of the New Citizens' Social Mentality and Social Adaption}

The testing result of the new citizens' social mentality indicates their low-level sense of social fair. It is probably due to the exploitation on them in the process of urbanization, misdistribution of the social resources and rights, and the widening gap between rich and poor etc. Previous researches showed that sense of social fair is the core factor to affect sense of life satisfaction, citizens' behavior, the prosocial behavior and social adaption. High-level sense of social problem suggests that the citizens experiences severe mood on problem. People feel perplexed on the rising price of commodities, gap between rich and poor, housing and employment problems, which, at the same time, is the life-and-death problems to determine whether the new citizens can live in the city or not. After analysis, we found that the sense of social problem is related to educational level: those who have junior college degree or above have higher sense of social problem than those who have at most received high school education. High educational persons are prone to be impulsive between ideal self and real self, which would result in more social problems if the two sides cannot be balanced effectively. This is in line with the conclusion drawn by Liu Guoyi and Gao Yanhua (2007) after their study on the medical school students of different education level [20].

The testing results on the social adaptation of the new citizens suggest that the new citizens cannot adapt well as a whole. And the scores on subscales of social adaptation are below the average, which is in line with previous studies. For instance, some scholars did a research on the social adaptation of the Three Gorges Reservoir migrants, migrant workers and landless farmers. The findings are that the migrants of reservoir areas cannot adapt well economically and mentally [21]; the adaptation of migrant workers is at a lower level [22]; landless farmers' vocational adaption is at an average level while they have difficulty in social interaction [23]. Besides, education level, time of transferring residence registration and economic situation are obviously connected with the social adaption. After further analysis, educational level influences the four subscales a lot on social adaptation, work adaptation, interpersonal adaptation, values for adaptation and psychological adaptation. And those who have bachelor degree or above score higher in social adaptation, 
interpersonal adaptation and psychological adaptation than those who went at most high school and score higher in work adaptation and values for adaptation than those who at most went junior colleges, which is also in line with the correlation research conclusions. For example, Tan Ping and Peng Haoxiang (2009) indicated that the overall adaptation of migrants of reservoir areas including natural adaptation, interpersonal adaptation, living custom adaptation and labor form adaptation is influenced by education level. And the adaption level of those who have gone to junior colleges or above is higher than that of middle school and primary school [24].

\subsection{The Relationship between Social Mentality and Urban Social Adaption of the New Citizens}

This study shows that sense of life satisfaction, sense of social stress, sense of trust in the government, sense of social fair and sense of social safety are all relevant with social adaption closely. The combination of high sense of life satisfaction, low sense of social stress, high sense of social fair and high sense of social safety is tend to be better adaption than its opposite combination. Sense of life satisfaction, sense of social stress, sense of social fair and sense of social safety are dominant factors to affect the social adaption of the new citizens, and they all account for the $29.5 \%$ of variances in total. Through his study on the ecological migrants of "San-Jiang-Yuan", Shi Desheng (2009) found immigration to the living environment satisfaction and the sense of the social problem has a great influence on the social adaptation [25]; Liu Zhen and Lei Hong studied the Three Gorges migrants and indicated that social mentality is the base of subjective active social behavior to adapt to the new environment [17]. The conclusions above are all in line with our conclusion that there is a close relation between social mentality and social adaptation. Meanwhile, the further analysis on the subscales of social mentality and social adaption suggests that new citizens' combination of social mentality factors can account for $8.4 \% \sim 36.5 \%$ to social adaptation and variance of the subscales. In view of the numerous factors influencing social adaptation, the $8.4 \% \sim 36.5 \%$ 's variance shows that the combination of social mentality factors can help to predict the social adaptation, psychological adaptation, work adaptation, environmental adaptation and values for adaptation.

\subsection{The Limitation and Prospect of this Study}

This study adopted the self-assessment questionnaire method, which is apt to make mistakes like common method bias and cause research results unreliable. As for the future study, advance control and afterwards control should be adopted to minimize deviations. In addition, the sample of this study is taken only from Chongqing Municipality and may be lack of representativeness. In the future, the range and quantity of the sample should be enlarged to promote the ecological validity of study.

\section{Conclusion}

The findings from this study are as follows: Firstly, new citizens scored higher on the scales of sense of trust in the government, sense of social problem and sense of social stress, while their score of sense of social fair is quite lower. The situation of new citizens' adaptation to urban society was poor, which is especially prominent on their work adaptation and values for adaptation. Secondly, the higher their education, the longer they transformed their rural household registration systems into urban and the better status of economic, the higher the score of their social adaptation. Thirdly, social mentality of new citizens had a significant predictive effect to their own unban social adaptation. What's more, sense of life satisfaction, sense of social fair and sense of trust in the government were significant positive predictors; sense of social stress and sense of social problem were remarkable negative predictors.

\section{Acknowledgements}

The authors would like to thank the reviewers for their helpful comments and suggestions on this research. And thank Yalin Hu, Liu Tan, Sichen Zhou, Li Xue, and Yulian Deng for their help in translation. This work was substantially supported by a grant from the National Social Science Found Project (11XSH019), and Key research project from key research base of Chongqing humanities and social sciences: "Status and Strategy of New Citizens' Adaption to Urban Society in Chongqing" (10SKB22)

\section{References}

[1] Yang, Y.-p., \& Jin, Y. (2006).A review of the research on social adaptation. Psychological Science, 29, 1171-1173.

[2] Arthur, S. R. (1995). The Comprehensive Dictionary of Psychology. SH: Shanghai Translation Publishing House.

[3] Zhu, Z.-x. (1989).The Comprehensive Dictionary of Psychology, BJ: Beijing Normal University Publishing Group.

[4] Lukash, E. I. (2005). Attitudes toward the social adaptation of creatively gifted children in Russia and the United States. Russian Education \& Society, 47(11), 57-70.

[5] Chen, J. - w., \& Wang, T. (2003). On Social Adaptation: Mental Mechanism, Structure and Function. Journal of Educational Science of Hunan Normal University, 2(4), 90-94.

[6] Jia, X.-b. (2001)The natural and mechanism of mental adaptation. Journal of Tianjin Normal University (Social Science), 154, 19-23.

[7] Xiang, H.-y., Hu, W.-d., Li, X.-j., Hou, X.-h., \& Wang, T. (2009). Study on Quality of Life of Elderly Population and Relevant Influential Factors. Practical Preventive Medicine, 16(4), 996-999. 
[8] Ye, J.-h. (2008). The Plight and Its Way out in Landless-farmer's City Adaption. China soft science magazine, (1), 1-6.

[9] Feng, X.-t. (2006). Social Adaptability of First Generation Urban Single Children in China. Educational Research, 26(10), 28-34.

[10] Chen, J. - w., \& Wang, T. (2004). Social Adaptation and Mental Health. Journal of Southwest China Normal University (Humanities and Social Sciences Edition), 30(3), 34-39.

[11] Engel, G. L. (1977). The need for a new medical model: a challenge for biomedicine. Science, 196, 129-136.

[12] Bartol, C. R., \& Bartol, A. M. (1999). Criminal behavior: A psychosocial approach (p. 231). Upper Saddle River, NJ: Prentice Hall.

[13] Wang, Y.-f., \& Pan, X.-f. (2013).The Experience Structure of Chinese Social Mentality and the Development of Its Measurement. Psychological Exploration, (1), 79-83.

[14] Chen, J.-m. (2009). A Review of research on social mentality. Academic Research, (7), 36-41.

[15] Li, L,-w., \& Yu, C. (2006). The Urban Adaptability of the Peasant-workers of the New Generation. Youth Studies, 04.12-15

[16] Tang, L.-p. (2005). The Marginalized Self-recognition of Inter-provincial Migrants in the Three Gorges Area and Its Determinants. Chinese Journal of Population Science, (2).

[17] Liu, Z.,\&Lei, H. (1999). Three Gorges migrants' social mentality in social adaptability. Population Research, (2): $18-23$
[18] Du, K., \&P, X.-f(2014).The Scale Development of New Citizens' Adaptation to Urban Society in the Process of China's Urbanization. Psychology and Behavioral Sciences,3(3): 93-99.

[19] W, Y.-f., \&P, X.-f. (2013).The Experience Structure of Chinese Social Mentality and the Development of Its Measurement. Psychological Exploration, (1), 79-83.

[20] Liu, G.-y., Gao, Y.-h, Zhang, Y.-e., \&Hao, Y.-j. (2007).Mental state and suicidal attitude of medical students in different educational levels: A cluster random sampling investigation. Journal of Clinical Rehabilitative Tissue Engineering Research, 11(39), 7855-7858.

[21] Feng, X.-t. (2004). "Falling to the Ground and taking Roots"? — Adaptation of the rural migrants of the Three Gorges. Sociological Research, 5, 19-27.

[22] Xu, C.-x. (2008).Falling to the Ground, but Taking No Roots-The Urban Adaptability of the Peasant-workers of the New Generation. South China Population, 22(4), 52-59.

[23] Li, F, \& Zhong, Z.-b. (2010). Social Adaptation of Lost Land Peasants in the Process of Urbanization: Investigation on Two Communities with Lost Land Peasants in Yangzhou Jiangsu Province. Youth Studies, (2), 84-93.

[24] Tan, P., Peng, H.-x., \&Zhang, G.-b., (2009). Investigation into Hubei Three Gorges Migrants' Adaptability to Society and its Reflection. Journal of China Three Gorges University (Humanities \&Social Sciences), 31(3), 15-18.

[25] Shi, D.-s. (2008) . Living Condition and Social Adaptation of "San - Jiang - Yuan" Ecological Migrants: Based on "Chang - Jang - Yuan" Ecological Immigrants settlement in Germu City. Tibetan Studies, 4, 93-103. 